\title{
Calibration Factor
}

National Cancer Institute

\section{Source}

National Cancer Institute. Calibration Factor. NCI Thesaurus. Code C69285.

A multiplication factor used to obtain an estimated real-world value from a measured or calculated value. 